\title{
A CASE OF PATENCY OF THE PERICARDIUM AND ITS EMBRYOLOGICAL SIGNIFICANCE
}

\author{
R. A. McGARRY \\ Department of Anatomy, University of Michigan \\ ONE FIGURE
}

During the winter of 1913 there was found in our laboratory an infrequent malformation of the pericardium in which there existed a large foramen, connecting the pericardial sac with the left pleural sac. Besides this condition there also occurred other anomalies of the coelomic derivatives, which if correctly interpreted, point back to an early disturbance in the development of the general coelomic cavity. On account of the rarity of this condition, and on account of its broad embryological significance, it was thought that the following report would not be out of place.

Briefly, the history of the case is as follows: Male, sixty-five years old; family history not obtained. After being in the Newberry State Hospital for eleven years, suffering from terminal dementia, the patient died with symptoms of gastritis. Death occurred in 1913. During his residence at the hospital no symptoms were observed which would point to the condition we are describing.

On examination of the body during the process of dissection the rare condition was found of a large pleuro-pericardial foramen. In addition to this there was also found a group of peritoneal disturbances; namely, a ventral hernia, left inguinal hernia, tendency to double femoral hernia, and malposition of the colon. They will be described in that order.

The opening between the pericardial and pleural sacs appeared as an opening from 7 to $8 \mathrm{~cm}$. in diameter. The edge was free throughout its course, which extended from above the pulmo- 
nary artery, thence over the root of the lung. From there it arched slightly forward, following the groove between the systemic and pulmonary aortae. At the junction of the pulmonary artery with the right ventricle the fold turned downward and backward, then upward to terminate back of the left atrium. The free edge continued laterally to the left, forming the left.

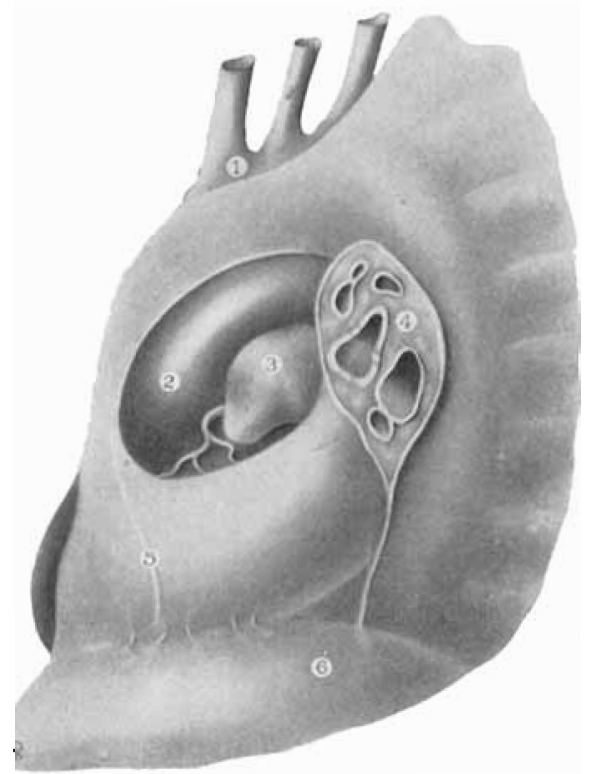

Figure 1. Left pleural cavity viewed from the left side, with the left lung removed. The large foramen in the mediastinal pleura, in front of the root of the left lung opens directly into the pericardial sac, exposing the heart; 1 , arch of aorta and large vessels; 2 , pulmonary aorta; 3 , left auricular appendage; 4 , root of left lung; 5 , left phrenic nerve appearing through the left mediastinal pleura; 6 , diaphragmatic pleura.

parietal layer of the pericardjum, and to the right, forming the right costal pleura. Through the opening could be seen the pulmonary artery and left auricular appendage, as shown in figure 1. The left phrenic nerve passed between the two layers of the anterior edge of the foramen. Aside from the large opening in it, the pericardium was normal. There were no signs of adhesions or other disease except for a few adhesions over the apices 
of the lungs. The upper lobe of both right and left lungs was partially divided in each case, by a fissure from 1 to $2 \mathrm{~cm}$. deep. Nothing abnormal was found regarding the diaphragm.

On examination of the peritoneum there was found a small ventral hernia, $1 \mathrm{~cm}$. from the median line midway between the umbilicus and xiphoid cartilage. It pierced the transversalis fascia, both layers of the rectus sheath and the rectus muscle, appearing beneath the skin. The opening was $1 \mathrm{~cm}$. in diameter. Through the opening protruded a tag-like appendage which appeared to be made up of a portion of the falsiform ligament of the liver. A small vein and artery passed into it from the internal mammary vessels. The left inguinal hernia was a very large oblique hernia extending down to the bottom of the scrotum. It contained a large fold of the great omentum. In the region of both femoral rings there were distinct short funnelshaped pockets of the peritoneum extending into the femoral canals.

The malposition of the colon was determined by the abnormal disposition of its peritoneal reflections. The peritoneal covering was more complete than usual. Thus the caecum and part of the ascending colon were completely surrounded, and were suspended free in the cavity by a mesentery. The ascending colon was flexed ventrally and upward upon itself so that the caecum was lying above the right lobe of the liver. The vermiform appendix, $10 \mathrm{~cm}$. long, was found beneath the junction of the sixth costochondral articulation, at the level of the xiphoid cartilage of the sternum. It passed down medially between the caecum and ascending loop of the sigmoid. The sigmoid colon formed a large loop with a broad mesentery. The upper limb of the flexure extended obliquely upward across the umbilical and hypogastric regions into the right hypochondrium, where it, together with the caecum, caused a marked depression upon the anterior surface of the liver. The flexure turned here and the lower limb passed downward and backward through the right hypochondrium, and from thence downward into the true pelvis, having formed a loop about 16 inches long. It was supported throughout its whole length by a mesentery. The great omen- 
tum was much enlarged and formed, as has been mentioned, the contents of the left inguinal hernal sac.

On examination of the literature I have been able to find eighteen cases of defective pericardium. Three of these were found in foetuses and the remainder in adults. I have been able to examine the original articles of nine of these cases. Of the remaining nine, five were found in descriptions given by other writers, while the last four could not be utilized as the descriptions and references were either incomplete or the source unavailable. The nine cases, the accounts of which I have had access to, are as follows:

Baillie (1788) reported a condition in a male of forty, in which the heart was found to lie free in the left pleural cavity. The mediastinum consisted of two laminae of pleura, inclined to the right side of the chest. Both laminae were connected throughout their extent by the intervention of a cellular membrane. This passed over the vena cava about 1 inch above the auricle. The heart was involved in the reflection of the pericardium, which became its immediate covering. This covering was very thin. The left phrenic nerve ran between the two laminae almost immediately under the sternum.

Curling ('39) reported a case in which, upon opening the chest, the heart was found completely exposed, lying loose in the cavity of the left pleural sac. There was no appearance of any pericardium covering the heart. The only indication of a pericardium was a reflected fold which covered the pulmonary vessels on the right side. The fold on the right side, close to the diaphragm, presented a small serous pouch with defined margin inferiorly and into which the appendix of the auricle protruded. The anomaly was discovered in a male of forty-six.

Baly ('50) reported a case of malformation of the pericardium in a male aged fifty-two. The malformation was discovered during a postmortem. The heart and left lung were were found to be in the left pleural sac. The heart was in close contact with the lung, but connected in no way with the diaphragm. The membrane forming the common sac constituted the pleura of the lung in one case, and the pericardium in the other. The mem- 
brane continued in the horizontal direction, after leaving the sternum lined the ribs on the left side, covering the outer and posterior surfaces of the lung. On its inner surface it was reflected at the root of the lung, directly upon the pulmonary veins, thence to the right pleura. The left lung was described as being covered by a false membrane. The phrenic nerve passed in front of the arch of the aorta to reach the septum between the two pleural sacs.

Bristowe ('54) reports a peculiar pericardium found in a male of twenty-eight. The heart was much enlarged. The heart and left lung were both contained in the left pleural cavity. The lower part of the lobe of the left lung was firmly attached to the anterior surface of the left side of the heart. A fold of membrane existed at the upper right side of the heart. It commenced at the pulmonary artery, passed over the aorta and vena cava, descending to the diaphragm. From this point it was lost in the root of the left lung. The fold consisted of fibrous tissue covered on either side by pleura. It was widest at the right auricle, where it was about 1 inch in depth. The fold was adherent to the heart in several places. The right phrenic nerve took its normal course, but the left passed down between the layers of the membrane, about one-half inch from its edge.

Powell ('68) reported a case in which a foramen connecting the pericardium and left pleura was found. The communication was situated above, and anterior to the root of the lung. It was small and oval in shape, being less than 1 inch in diameter. There were no adhesions, and the pleura in general was very thin. The left lung was found collapsed, the pleura containing a little fluid. The pericardium contained some air and a little fluid, the heart being compressed backward. To all appearances the opening was a congenital one.

Bjornstrom ('71) reported an anomaly which occurred in a female of forty. Only about one-third of the right side of the heart was covered with pericardium. The remainder lay free in the left pleural sac in direct contact with the lung. A large foramen connected the pericardial and left pleural sacs. Only that portion of the parietal pericardium was found which formed 
the wall between the right lung and heart. The portion which was back of the right auricle went over into the visceral leaf and surrounded the heart on the right side; from here it passed on to the sternum, where it continued as the left pleura.

Primrose ('01) reported a patency of the pericardium occurring in a male of sixty. An opening existed between the pericardium and left pleura which was about 3 inches in. diameter. The structures which showed through the foramen were as follows: aorta, from its appearance to about 1 inch beyond origin of the left subclavian artery; pulmonary aorta, from its origin to its bifureation; and the left auricular appendage. No indications of adhesions were present. A number of other anomalies were present which involved principally the genito-urinary system.

Keith ('07) reported two cases of malformation of the pericardium. The first case of deficiency of the pericardium was found in an anencephalic full-term child. The opening, just anterior to the root of the left lung, was about 1 inch in diameter, and through which the left auricular appendage protruded. It had a round smooth margin. The phrenic nerve descended in the anterior free edge of the foramen.

The other case occurred in a foetus, the subject of numerous malformations. It presented a large deficiency on the left side. Upon removal of the sternum a strong fibrous membrane was found behind it, upon which the phrenic nerve descended. This proved to be the pericardium, which descended and divided, the left margin passing in front of and below the left lung. Turning back at the lower margin, it appeared as a fold extending up from the diaphragm. The greater part of the left pleural cavity being occupied by the liver, stomach and spleen.

The five cases to which reference has been made by other writers included one in which the heart was found lying free in the left pleural cavity, devoid of pericardium, that was reported in the Philosophical Transactions, London, 1740, and referred to by Baillie in 1788. The same author refers to similar cases recorded by Columbus, Bartholinus, and Littre, in which no details were mentioned. Peacock ('68), in his work on the malformations of the human heart, refers to a case by M. Breschet ('26), in which the 
absence of the pericardium occurred in a male of twenty-eight. Another case was reported by Hud in 1848. He also mentioned a specimen in the St. Thomas Museum, London. Peacock mentions a case found by himself in a man of seventy-five. $\mathrm{He}$, however, did not describe it. There were three cases of malformation of the pericardium for which I have not been able to get the original articles, the titles of which are given in the references at the end of this paper.

Not including my own case, we may summarize the literature of the malformation of the pericardium as follows: (a) two cases of supposed complete absence of the pericardium; (b) seven cases of incomplete pericardium, which is represented by a small fold of tissue along the posterior wall; (c) three other cases of incomplete pericardium, in which exịsted a distinct opening between the left pleural sac and pericardial sac, varying in diameter from less than one-half inch to over 3 inches; in six cases the condition was not definitely described, the only mention made being of both heart and lung lying in the left pleural sac.

The only attempt by any of the writers to explain these cases on an embryological basis, was made by Keith. This writer attributed the patency to, "an extension of the lung bud growing into and expanding the communication between the pericardium and pleura."

Peacock thought that the pericardium developed as a continuation of the fibrous sheath of the vessels of the heart, which spread out over the heart, and formed its sac. He considered the foramen as due to a failure of fusion of the membrane on the left side.

None of the previous writers directed their attentions to the related serous cavities, and no examination was reported, of the peritoneum and its appendages.

Before entering into the embryological significance of the malformations it may be well to give a brief review of our present knowledge of the development of the coelom. It was early shown by His that the body cavity in the early embryo is divided into the pericardial and trunk cavities. The communication between these spaces is called the parietal recess. The parietal 
portion originally contains the heart, and is destined to become the pericardial coelom. A portion of the parietal recess forms the pleural cavity; it surrounds the lung bud throughout its development, and becomes the pleural coelom. In the remainder of the parietal recess the liver and stomach develop, but are later evaginated and become part of the abdominal coelom.

For our knowledge of the details of the separation of these cavities we are indebted to Mall. He showed that at about the end of the fifth week, while the body is yet kinked upon itself, the line of separation appears between the pericardial and pleural coeloms. This is due to a constriction of the walls along the ductus Cuvieri, which lies on a ridge of tissue encircling the canal of communication between the two cavities. 'This forms the beginning of the pulmonary ridge. This ridge appears as a small elevation, in the sagittal plane of the body, running from the lobe of the liver, along the dorsal wall of the ductus Cuvieri, to the dorsal attachment of the mesocardium. Lying in the sagittal plane of the body opposite the fourth and fifth cervical nerves it receives into its substance the phrenic nerve, which passes posterior to the ductus Cuvieri.

Soon the lung bud, which has heretofore hung free in the pleural coelom beneath the, pulmonary ridge, grows outward against it and causes it to bulge. With the rotation of the liver towards the head the ridge is divided into two parts: (1) the cephalic which has included in it the phrenic nerve, and ductus Cuvieri, and which later becomes the pleuro-pericardial membrane; (2) the caudal portion, which remains at the caudal end of the septum transversum and liver, on the one hand, and the body wall on the other. It later forms the pleuro-peritoneal membrane.

The pulmonary ridges from their beginning to their separation into the pleuro-pericardial and pleuro-peritoneal membranes appear as two ear-like projections from the septum transversum, extending along the ductus Cuvieri. They appear in the sagittal plane of the body at right angles to the plane of the septum transversum. The growth of the pleuro-pericardial membrane in the direction of the head and the growth of the pleuro-peritoneal membrane caudally results in a widening of the dorsal projection 
of the septum transversum. The lung burrows into this space throwing the pleuro-cardial membrane and phrenic nerve to its medial side. Up to this time there has been a mere slit where the pleuro-pericardial membrane comes in contact with the root of the lung. At the time of closure the small ridge or pleuro-pericardial membrane, is very insignificant, its extension being due to a rapid growth of the lung.

Brachet showed that the canal connecting the cavities was only constricted by the ductus Cuvieri, its complete closure being due to an active growth of the anlage of the pleuro-pericardial membrane, which takes place at about this time. This completely separates the pericardial from the pleural cavities. Immediately after this the rotation of the liver and setum transversum takes place which changes the relation of the pleuro-pericardial membrane from parallel to right angles to it. By this time the pleuro-peritoneal membrane stretches across the body to the tips of the embryonic ribs, thus completely closing off the abdominal cavity. This also alters the position of the phrenic nerve.

With the steps of the development of the coelom in mind, we are in position to understand something of the manner of occurrence of defects in the pericardium and other coelomic derivatives. In my own case it is evident that there was a general involvement of the coelom. We are not accustomed to thinking of pathologic processes in the embryo limited to the developing coelom, but it is evident that such must exist. It is well known that the neural plate passes through a period when it is particularly sensitive to injury while the adjacent tissues are unaffected, and thus we have a group of pathological conditions, as anencephaly, spina bifida, etc., that date from this period. In a similar way it is reasonable to suppose that the cells lining the coelomic space, may at some period be particularly sensitive, and abnormal conditions occurring at this time, would result in disturbances, either an over production or an under production, of the serous derivatives. Thus we might naturally expect congenital hernias, gastroptosis, enteroptosis, and other abnormal conditions of the peritoneum, occurring at the same time with abnormal conditions of 
the pericardium and pleura, which condition is well illustrated in our case. The occurrence of a patent pericardium is one aspect of a general condition. It is possible also in our case that in the process of subdivision of the general coelomic spraces an undue proportion was constricted off by the lower limb of the pulmonary ridge, resulting in an over production of peritoneum, and an under production of thoracic serous membrane.

Those cases in which a foramen occurred, including the one found in our laboratory, between the pleura and pericardium seem to be explained by supposing that in the early development of the embryo, some slight injury occurred to the general coelom, which resulted in a lack of development of the pleuro-pericardial membrane. The membrane, which was to form the wall between the heart and lung failed to fuse with the root of the lung bud, and the pleuro-pericardial foramen resulted. This view is also supported by the position of the phrenic nerve.

The explanation given by Keith ('06), according to whom the foramen was due to the presence of the lung which kept the communication between the pleural and pericardial cavities open, could hardly be the cause, as the lung bud forms subsequent to the development of the fold, which separates the cavities.

The case in which only a small portion of the supposed pericardjum was found, existing as a ridge or fold at the base of the heart, seem to be readily explained. It at once suggests itself that the condition, with which we were dealing, was due to a less complete separation of the pleuro-pericardial membrane than occurred in those cases presenting a foramen. Thus the heart and lung would lie in a sac, which if it had separated, would have formed the pericardium and pleura, the fold or ridge of membrane existing at the base of the heart being the embryonic remains of the upper portion of the pulmonary ridge. The phrenic nerve in these cases was found under the sternum, probably never having been included in the substance of the pulmonary ridge.

Those cases in which a total absence of the pericardium was supposed to have occurred are explained as follows: The upper limb of the pulmonary ridge totally failed to develop. The con- 
dition there is apparent. The heart and lung lie in one sac, which if correctly named would be pericardial, inasmuch as the left pleural sac had never become separated off. These cases must not be confused or connected with the cases described by Todd ('13) and others regarding the absence of the pleural sac in certain mammals. In those cases the pleural sacs were originally present, but in later life became obliterated.

The second case reported by Keith ('07) forms an interesting variation. Here the lung, heart and liver were found all occupying the same cavity. This condition must be explained by the involvement of both the pleuro-pericardial and pleuro-peritoneal membranes. As has been noted, the pericardial defects always are found on the left side. This apparently is associated with the asymmetry of the liver, and its rotation during the course of development, which would put a greater tension on the left pulmonary ridge, and predispose this to the defect.

Before concluding I wish to express my obligations to Professor Streeter at whose suggestion this report was undertaken.

\section{CONCLUSIONS}

1. Pericardial defects result from a disturbance occurring between the fifth and seventh weeks of embryonic life.

2. These defects always occur on the left side.

3. Other coelomic disturbances of the same period occur in the form of peritoneal abnormalities, such as congenital hernia, gastroptosis and other abnormal arrangements, and distributions of the peritoneum.

4. Congenital pericardial defects have not yet been clinically diagnosed and apparently produced no functional disturbance. 


\section{LITERATURE CITED}

Baillie, M. 1793 On want of a pericardium in the human body. Tr. Soc. Imp Med. Chirurg. Knowledge, London, p. 102.

BALY, W. 1850 Absence of pericardial sac, the heart lying in the cavity of the left pleura. Tr. Path. Soc. London, vol. 3, p. 60,

BRACHET, A. 1897 Recherches sur l'eletion de la portion cephalique des cavites pleurales et sur le development de la membrane pleuropericardique. Jour. de l'anat. et physiol., vol. 33.

Buonnstrom, F. 1871 Defect in pericardium. Upsala Larkereforenings Forhandlinger, p. 261.

BrIstowe, J. S. 1854 Malformations of the pericardium. Tr: Path. Soc., London, p. 109,

Chiari, H. 1880 Ueber einen Fall von fast vollstandigem defekte des Pericardium parietale. Wien. Med. Wachnschr, Bd. 30, p. 372.

Curling, T. B. 1839 Want of a pericardium. Tr. Med. Chir. Society, London, vol. 22 , p. 222 .

GAY, M. 1899 Di una speciale anomalia del pericardio. Lavori d. Cong. d. med. int., Roma, vol. 8, p. 437.

Hewson, A. 1896 Absence of fibrous pericardium on left side. Proc. Assoc. Amer. Anat., Washington.

Кегтн, A. 1906 Partial deficiency of the pericardium. Jour. Anat. Physiol, vol. 6 .

MaLL, F. P. 1901 On the development of the human diaphregm. Johns Hopkins Hosp. Bull., vol. 12.

1910 Die Entwicklung des Coeloms und des Zwerchfells. Handbuch d. Entwick. d. Menschen. Keibel u. Mall., Leipzig, vol. 1, pp. 527-552.

Peacock 1868 Malformations of the human heart. London.

Powell, D. R. 1868 Deficiency in the pericardium. Tr. Path. Soc., London, vol. 20, p. 99.

Primrose, E. J. 1901 Patency of the pericardium. Glasgow Med. Jour., vol. 56, p. 184.

Todd, T. W. 1913 Notes on the respiratory system of the elephant. Anat. Anz., Bd. 44. 